ERRATUM

S. Signorelli • M. R. Carroll

\title{
Experimental constraints on the origin of chlorine emissions at the Soufriere Hills volcano, Montserrat
}

Published online: 13 November 2001

(C) Springer-Verlag 2001

\section{Bull Volcanol (2001) 62:431-440}

In the printed version of the article in Table 1 a row of values for $\mathrm{wt} \% \mathrm{~K}_{2} \mathrm{O}$ was inadvertently omitted and some of the reported $\mathrm{Na}_{2} \mathrm{O}$ values were actually those for $\mathrm{K}_{2} \mathrm{O}$. The complete, correct table is reproduced below.

The online version of the article can be found at http://dx.doi.org/ $10.1007 / \mathrm{s} 004550000106$

\section{S. Signorelli}

Consejo Superior de Investigaciones Cientificas (C.S.I.C.) -

Institut de Ciènces de la Terra "Jaume Almera" -

Lluís Solé i Sabarís s/n, 08028 Barcelona, Spain

M.R. Carroll (®)

Dipartimento di Scienze della Terra,

Università di Camerino, 62032 Camerino, Italy

e-mail: carroll@campus.unicam.it

Tel.: +39-0737-402608 
Table 1 Analyses of major and trace elements (wt $\% \pm 1 \sigma$ on water-free basis with original analytical totals) from Soufrière Hills experiments (exp) and starting material $(\mathrm{sm})$. The experiments at higher pressure (100-250 MPa) were analysed at both 10 and $2 \mathrm{nA}$ (Morgan and London 1996)

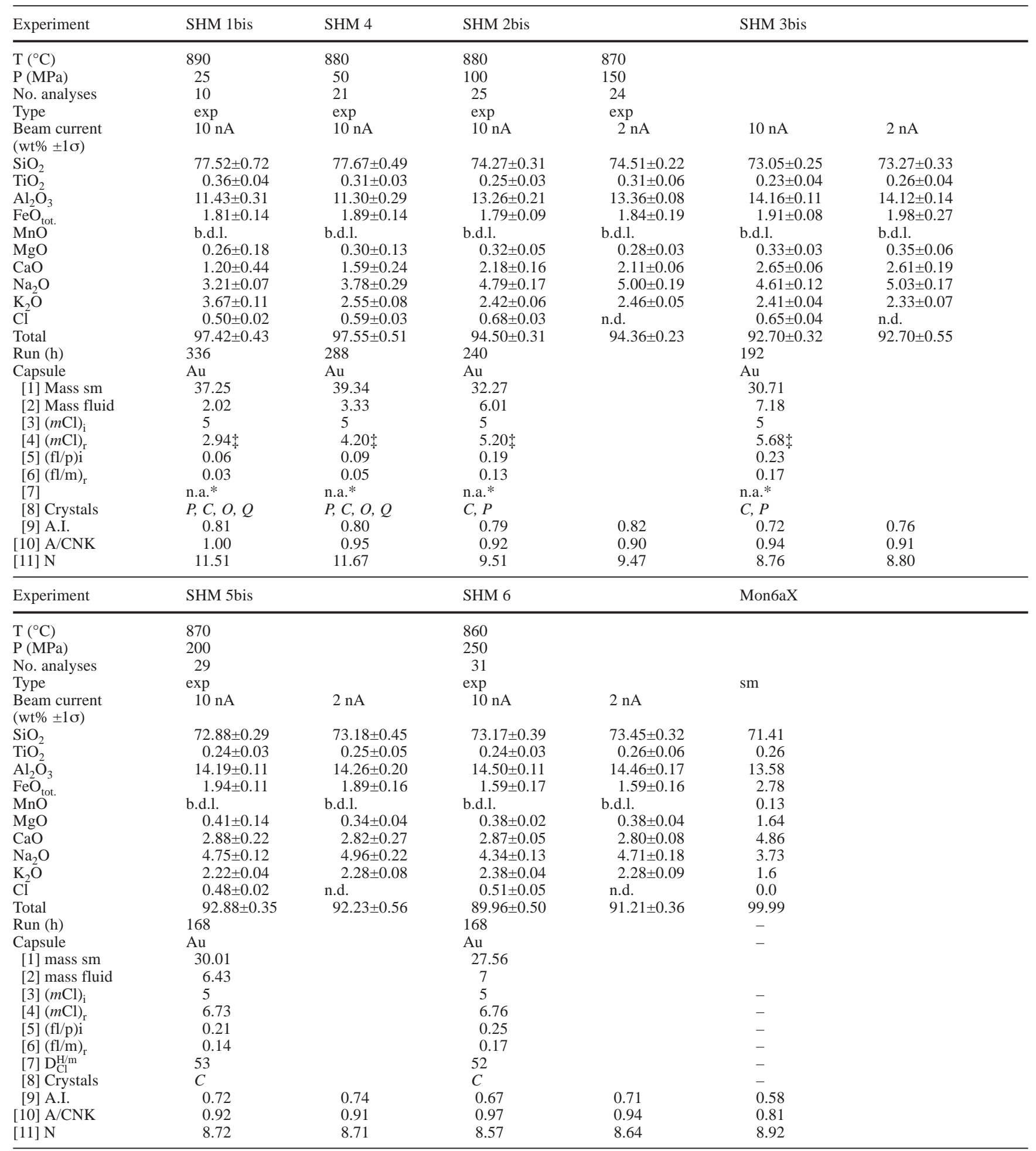

[1] mass (mg) of starting material powder; [2] mass (mg) of starting material fluid; [3] initial chlorine molality in the aqueous fluid phase; [4] chlorine molality in the aqueous phase during the run; $\$$ apparent $\mathrm{Cl}$ molality (see text); [5] initial fluid/powder ratio by weight; [6] fluid/melt ratio during the run by weight; [7] fluid/melt distribution coefficient; n.a.*, not applicable because values are meaningless for subcritical fluids - see text; [8] mineralogical assemblage after the run: $Q$, quartz; $C$, clinopyroxene; $O$, Fe-Ti oxides; $P$, plagioclase; [9] $\mathrm{Na}+\mathrm{K} / \mathrm{Al}$ molar ratio; $[10] \mathrm{Al} / \mathrm{Ca}+\mathrm{Na}+\mathrm{K}$ molar ratio; [11] Si/Al molar ratio. n.d., not determined. b.d.l., below the detection limit 